\title{
Assessment of Invitro Differentiation Potential of Canine Bone Marrow Derived Mesenchymal Stem Cells to Skeletal Myocytes
}

\author{
R. S. Sandhu ${ }^{1 *}$, N. S. Jadon ${ }^{1}$, P. Pandey ${ }^{2}$, D. Bodh ${ }^{1}$, P. Joshi ${ }^{1}$, \\ M. Kandpal ${ }^{1}$, R. Saini ${ }^{1}$ and A. Kumar ${ }^{1}$ \\ ${ }^{1}$ Deptartmen of Veterinary Surgery \& Radiology, ${ }^{2}$ Department of MBGE, CBSH, G.B.P.U.A. \\ and T., Pantnagar (U.S.Nagar), Uttarakhand (Pin: 263145), India \\ *Corresponding author
}

\begin{abstract}
A B S T R A C T
Mesenchymal stem cells are multipotent/pluripotent stromal cells that can differentiate into a diversity of cell categories depending upon the micro-environment to that they are exposed. The multipotent differentiation potential of MSCs is generally towards a constrained sum of cell types familiar to the tissue of origin and maintains the capacity for self-renewal. To assess the differentiation potential of MSCs to skeletal myocytes a male mongrel dog of 3 years was used to carry out the research. The marrow derived mesenchymal stem cells were harvested with mononuclear cells and cultivated in monolayer culture in T-25 tissue culture flasks till they attained of 80-90\% confluency. At $4^{\text {th }}$ passage the cells were driven towards skeletal myogenesis by addition of skeletal myocytes differentiation medium containing 5-azacytidine, foetal horse serum, basic fibroblast growth factor, dexamethasone and hydrocortisone. The cells which differentiated showed positive results of RT-PCR for the early myogenic differentiation factors Myf5 and Myogenin and Hoechst 33342 staining. The Hoechst 33342 stainin, RTPCR analysis and scanning electron microscopy leads to the positive result for differentiated skeletal myocytes in vitro. The differentiated skeletal myocytes can be used in tissue engineering and veterinary therapeutics for reparing the damaged skeletal myocytes.
\end{abstract}

\section{Introduction}

Mesenchymal stem cells (MSCs) or stromal progenitor cells is a population of stem cells. Mesenchymal stem cells regenerate tissues of mesenchymal lineages by differentiation, and trans-differentiate into cells derived from other embryonic layers, including neurons and epithelia in skin, lung, liver, intestine, kidney, and spleen. These cells form an elemental part of haemopoeitic micro environment which supports blood cell development. These cells are multipotent in nature as they can differentiate into some mesodermal lineages including adipocytes, osteocytes and chondrocytes . Additionally MSCs have a distinct artifice to suppress immuno mediated inflammatory responses (Griffin et al., 2013). Mesenchymal stem cells which are isolated from bone marrow have exhibited to infer a skeletal myogenic outcome (Mizuno, 2010). 
Moreover, substantiation that MSCs subpopulations may as well attribute diverse qualities and regeneration possibility has cropped up (Pérez-Silos et al., 2016). The trans-differentiated skeletal myocytes can be utilised as veterinary therapeutics for the use in inherited muscular disorders and also patients suffering from trauma due to accidents and other pathological condition concerning muscles. The differentiated cells from the same donor might help in early recovery from the pathological or inherited condition as compared to mesenchymal stem cells.

\section{Materials and Methods}

The present research was carried out in the Department of Veterinary Surgery and Radiology, College of Veterinary and Animal Science on a mongrel, intact, male adult dog of 3 years of age weighing $20 \mathrm{~kg}$ with apparently good general condition.

After keeping the dog off feed for atleast 12 hours prior to surgical manipulation, the required bone marrow aspirate was taken from the ileac crest or femur in either sternal or lateral recumbency respectively. The dog was subjected to the administration of atropine @ 0.04mg/kg B.W and diazepam @ $1 \mathrm{mg} / \mathrm{kg} \quad$ B.W intramuscularly as preanesthetic medications followed by $2.5 \%$ thiopental sodium intravenously to the effect as a general anesthetic for intubation and maintenance (Jadon et al., 1998). With a small incision, the ileac crest of the bone got exposed the marrow aspirate was collected with the help of $18 \mathrm{G}$ bone marrow aspiration/ biopsy needle (Rosanthel needle). The aspiration of $2.5 \mathrm{ml}$ of bone marrow sample into the cold heparinized low glucoseDulbecco's modified Eagle's medium (LDMEM) syringe locked to the bone marrow aspiration needle comprising of 1000 IU heparin was done.
A total quantity of $5 \mathrm{ml}$ marrow aspirate was collected from the animal. The buffy coat method of density gradient centrifugation technique was used for separation of mesenchymal stem cells in the bone marrow aspirate. The cells were cultured in T-25 flasks after formation of a pellet which was suspended in culture medium [(DMEM-LG containing $10 \%$ fetal bovine serum (FBS) and Antibiotic-Antimycotic solution (A mixture of 10,000 units $/ \mathrm{ml}$ of Penicillin, $10 \mathrm{mg} / \mathrm{ml}$ Streptomycin and $25 \mu \mathrm{g} / \mathrm{ml}$ Amphotericin B in $0.9 \%$ normal saline)]. The tissue culture flasks were maintained at $37^{\circ} \mathrm{C}$ in a humidified atmosphere of $5 \% \mathrm{CO}_{2}$ and $95 \%$ air in $\mathrm{CO}_{2}$ incubator. After the cells reached 80-90\% confluence cells were passaged using Trypsin-EDTA and they were observed for distinct morphological features and viability by "trypan blue exclusion test" (Strober, 2001).

The trypan blue dye solution was filtered and $10 \mu 1$ of the single cell suspension was pippeted in an eppendorf tube and amalgamated with $10 \mu 1$ of $0.4 \%$ trypan blue dye solution in ratio of $1: 1$ (dilution factor 2). The suspension was kept at room temperature for 5 minutes and 10ul of the suspension was encumbered into haemocytometer chamber. The cells were focused under a microscope with 40x and 10x lens and the counting of cells was done in the four WBC squares. Separate counting of the viable and nonviable cells was done. The number of cells per $\mathrm{ml}$ and percentage of viable cells were given by the formula (Monica et al., 2012):

Number of the cells per $\mathrm{ml}=$ (Total no. of cells/4) x dilution factor $\times 10^{4}$

Viable cell $(\%)=($ No. of the viable cells per $\mathrm{ml}$ ) / (total no. of the cells per ml) x 100

The cells were counted for their viability after first passage. 
After the cells reached about $60 \%$ confluence after $4^{\text {th }}$ passage the cells were exposed to skeletal myogenic differentiation media. For 48 hours the cells were grown in the mesenchymal stem cell culture medium, thereafter, the skeletal myogenic differentiation medium enhanced with 10 $\mu \mathrm{mol} / \mathrm{L} \quad 5$-azacytidine (Sigma-Aldrich, Bangalore, USA), $2.5 \mu \mathrm{g} \mathrm{L}^{-1}$ basic fibroblast growth factor (bFGF, Sigma-Aldrich, Bangalore, USA), $2 \%$ horse serum (HS) (Invitrogen, Carlsbad, CA, USA) was added to the tissue culture flasks to proceed for the differentiation process. The medium was changed after every 3 days. The cells were harvested at day 7,14 and 21. The cells which were grown to about $90 \%$ confluence without induction were considered as the control sample. In vitro differentiation of canine MSCs was characterized by Hoechst 33342 staining, polymerase chain reaction and scanning electron microscopy.

\section{Hoechst 33342 staining}

The dye stains the A and T segment of DNA present in the nucleus of skeletal myocytes and hence stain nucleus blue. The staining was performed at $21^{\text {st }}$ day of differentiation and cells were evaluated under inverted microscope.

\section{Preparation of dye from stock solution}

Hoechst 33342 dye stock solution was prepared by mixing the fillings of one vial $(100 \mathrm{mg})$ in $10 \mathrm{ml}$ of deionized water $\left(\mathrm{diH}_{2} \mathrm{O}\right)$ to generate a $10 \mathrm{mg} / \mathrm{ml}(16.23 \mathrm{mM})$ solution.

\section{Protocol for staining}

The trans-differentiated cells were fixed by 4\% paraformaldehyde after removal of culture medium from the flask. The staining solution was then poured into the culture flask. The culture flask was then incubated for 5-10 min at $37^{\circ} \mathrm{C}$ away from light. The cells were imaged under fluorescent microscope after removal of stain and washing it with DPBS.

\section{RNA extraction, one step reverse transcriptase-Polymerase chain reaction (RT-PCR)}

In a sterile nuclease free PCR tube a total volume of $50 \mu \mathrm{l}$ was formulated by adding nuclease free water in a amalgam of $4 \mu \mathrm{g}$ total RNA, $1 \mu 1$ of Reverse transcriptase enzyme, 1 $\mu \mathrm{l}$ random hexamer primer, $25 \mu \mathrm{l} 5 \mathrm{X}$ reaction mixture. The mixture was centrifuged for 30 seconds. Real Time - Polymerase Chain Reaction with the acceptable cycle condition was determined and utilized for each primer pair as follows: cDNA synthesis and predenaturation performed with 1 cycle of: $45-$ $60^{\circ} \mathrm{C}$ for $15-30$ minutes and $94^{\circ} \mathrm{C}$ for 2 minutes, PCR amplification performed with 40 cycles of: denature, $94^{\circ} \mathrm{C}$ for 15 seconds anneal, $55-66^{\circ} \mathrm{C}$ for 30 seconds extend, $68^{\circ} \mathrm{C}$ for 1 minute/kb, finally extension was done with 1 cycle of $68^{\circ} \mathrm{C}$ for 5 minutes. The oligonucleotide sequences of the gene used in PCR were as follows:

Myf5 (Mizuno et al., 2002) Forward $5^{0}$ CTGTCTGGTCCCGAAAGAAC- $3^{0}$ Reverse $5^{0}$-TGATTCGATCCAC TATGCTG- $3^{0}$ having amplicon length $500 \mathrm{bp}$, Myogenin (Ueda et al., 2002) (F) 5'- AGTGAC TGCAGCTCCCACAG -3' (R) 5'- GACG TGAGAGAGTGCAGGTT $-3^{\prime}$ having amplicon length 438 bp GAPDH -5'CCCATC ACC ATC TTC CAG GA -3' 5'TTG TCA TAC CAG GAA ATG AGC -3' having amplicon length $731 \mathrm{bp}$.

PCR products were analyzed by electrophoresis on $2 \%$ ethidium bromide incorporated-agarose gel in Tris-Boric-EDTA (TBE) buffer under UV transilluminator. 


\section{Scanning electron microscope}

The cells were harvested on day 21 and fixed in Karnovsky's Fixative for 24 hours. Further the cells were rinsed in 0.1 M PBS and dehydrated in ascending series of graded ethyl alcohols viz. 30\%, 40\%, 50\%, 70\%, 80\%, $90 \%$ and absolute alcohol for 10 minutes in each and critical point drying was carried out. The sample was dehydrated and dried the sample was partitioned in $1 \mathrm{~mm}$ to $2 \mathrm{~mm}$ sizes and put onto the stabs with the help of an adhesive tape. The stabs were then placed into the gold plating machine so as to cover the surface of the sample with gold to prevent any damage to the sample. After the gold plating was performed the samples were visualised under the scanning electron microscope to characterise the trans-differentiated skeletal myocytes. Data collected were expressed as per the method described by Snedecor and Cochran (1994).

\section{Results and Discussion}

The anaesthetic amalgamation of atropine, diazepam and thiopental sodium produced satisfactory plane of anaesthesia which confirms the findings of Jadon et al., (1998). Mesenchymal stem cells were isolated from the bone marrow aspirate by 'buffy coat' protocol as previously also demonstrated by Klepsch et al., (2013) although some modifications were made in this protocol. The adhered cells were considered as the population of mesenchymal stem cells as it is previously also observed by Ghiban et al., (2010). Trypan blue dye exclusion test was also performed for determining the number of viable and non-viable cells in the cell suspension and also to determine the number of cells per $\mathrm{ml}$ in the suspension.

The dilution factor used in this experiment was 2 . The cell viability $\%$ of 4 samples of canine MSCs was calculated at passage 1 .
The average cell viability $\%$ was found to be $98.15 \%$ and thus good to be used in this study. The shape of the isolated stem cells was elongated, which was found in accordance with the results found out by Huang et al., (2015). . Multiple cell layers and dense cell nodules were formed in some areas of the culture dish which confirm the findings of Huang et al., (2015).

The variation in the shape of cells was observed at every passage which revealed that there is an increase in cells width at centre at every growing passage. The cells from elongated in $1^{\text {st }}$ passage transformed to polygonal shape in $4^{\text {th }}$ passage.

The canine BM-MSCs were cultivated in the differentiating medium for a period of 21 days as previously described by Du et al., (2014). The mesenchymal stem cells in the differentiation media assumed a fairly uniform elongated, bipolar or tubular morphology within 48-60 hours of addition of differentiation media and by 5-7 days these cells assumed a sequence of linear adjacent arrangement with the appearance of bands of trans-differentiated skeletal myocytes across the flask (Figure 1). The cells grew long fusiform gradually and were neatly arranged as a muscular tube like structure, the cells also assumed multinucleated structure which is also a sign of differentiation of skeletal myocytes. This arrangement was found alike to that of myotubes formed by fusion of myoblasts (Merrison et al., 2012).

Hoechst 33342 stain binds into the minor furrow of DNA and demonstrates discrete fluorescence emission spectra that are reliant on dye:base pair ratios. The transdifferentiation assessment of cells by Hoechst 33342 stain was done at $21^{\text {st }}$ day. The staining of nuclei was performed and all nuclei were visualized by Hoechst 33342 staining (Figure 2). 
RNA of the trans- differentiated cells was extracted using HiPura mini kit .The samples were tested for Myf5 gene (Mizuno et al., 2002), Myogenin (Ueda et al., 2002) and GAPDH (a housekeeping gene), after 14 and 21 days. The primers for the genes Myf5 and myogenin being the markers of early myogenesis in the cell cultures gave strong bands against their respective base-pairs after 14 days of their treatment in the skeletal myogenic differentiation medium. Hence it was observed that the cells transdifferentiated into primitive skeletal myocytes as they expressed these 2 genes as previously reported by Gang et al., (2004). The gene expression of the marker related with skeletal myogenic differentiation Myf5 and myogenin was manifested in trans-differentiated cells and not in undifferentiated mesenchymal stem cells while GAPDH, being a housekeeping gene was apparent in both trans-differentiated and undifferentiated cells (Figure 3). The Polymerase chain reaction result of Myf5 and myogenin genes revealed a sturdy band in the trans-differentiation induced cells which validate the findings of Zuk et al., (2002).

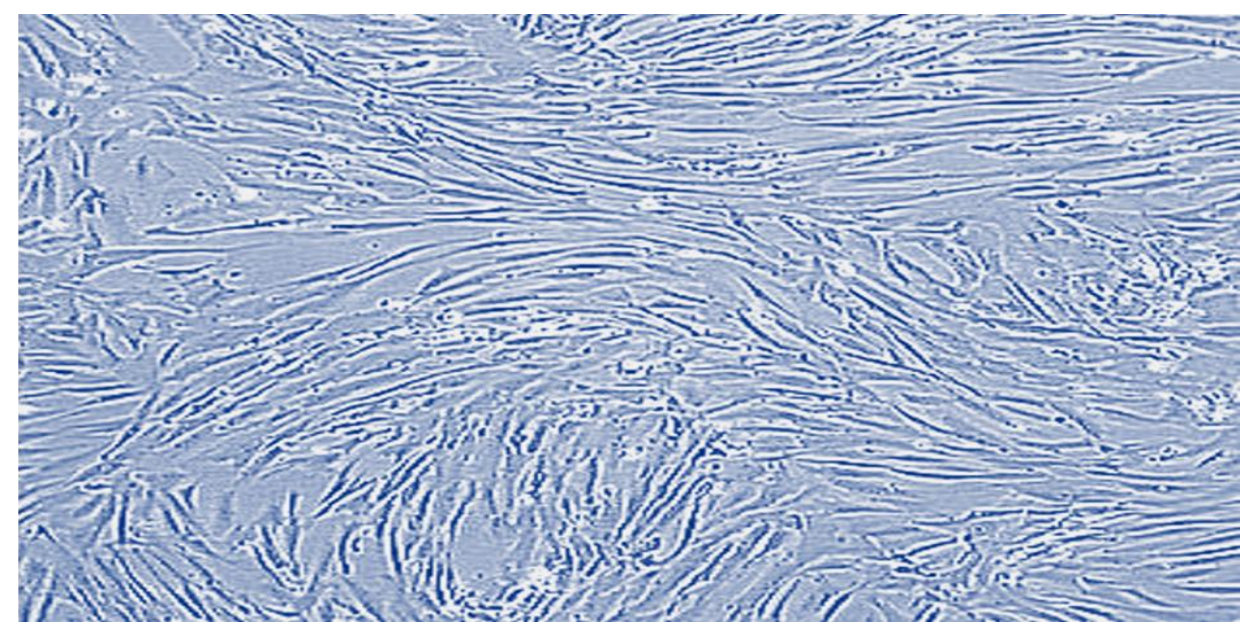

Fig.1 Morphology of of canine bone marrow derived mesenchymal stem cells in T-25 culture flasks after addition of skeletal myocyte differentiation medium, the cells are visible with striations and aligned longitudinally to each other (at 10x plus 10x magnification)

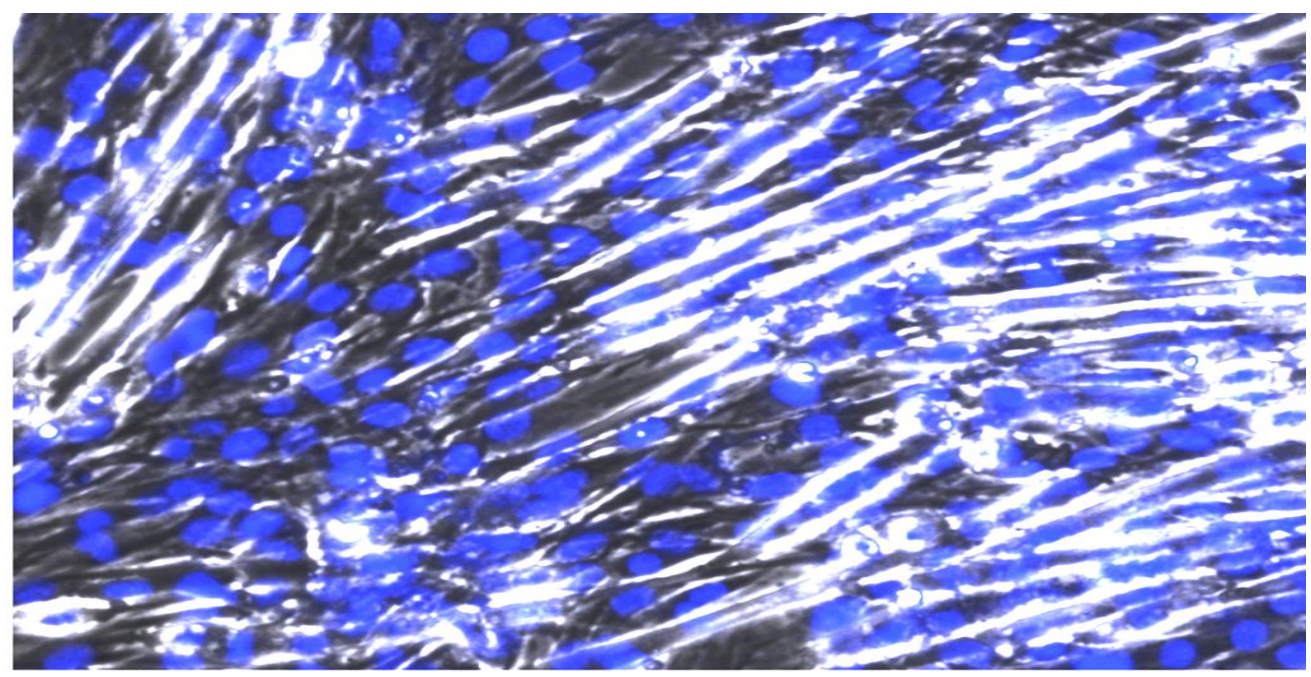

Fig.2 The staining of nuclei by Hoechst 33342 staining revealed the presence of multinucleated cells (the blue coloured are nucleii) 
(a)The RT-PCR analysis of Myogenin gene

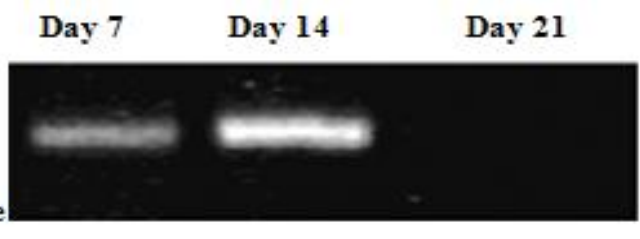

(b)The RT-PCR analysis of Myf5 gene

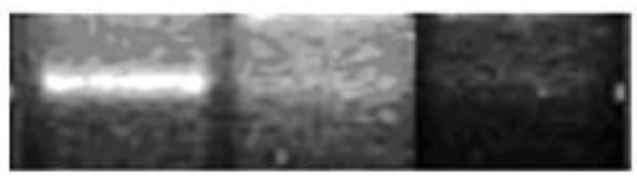

(c)The RT-PCR analysis of GAPDH gene

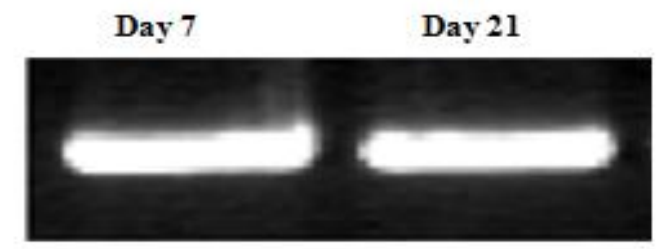

Fig.3 The RT-PCR analysis of the differentiating samples at day 7, day 14 and day 21 for the genes Myogenin and Myf5(a \& b) in differentiating samples. The RT-PCR analysis of house keeping gene GAPDH at day 7 and day 21

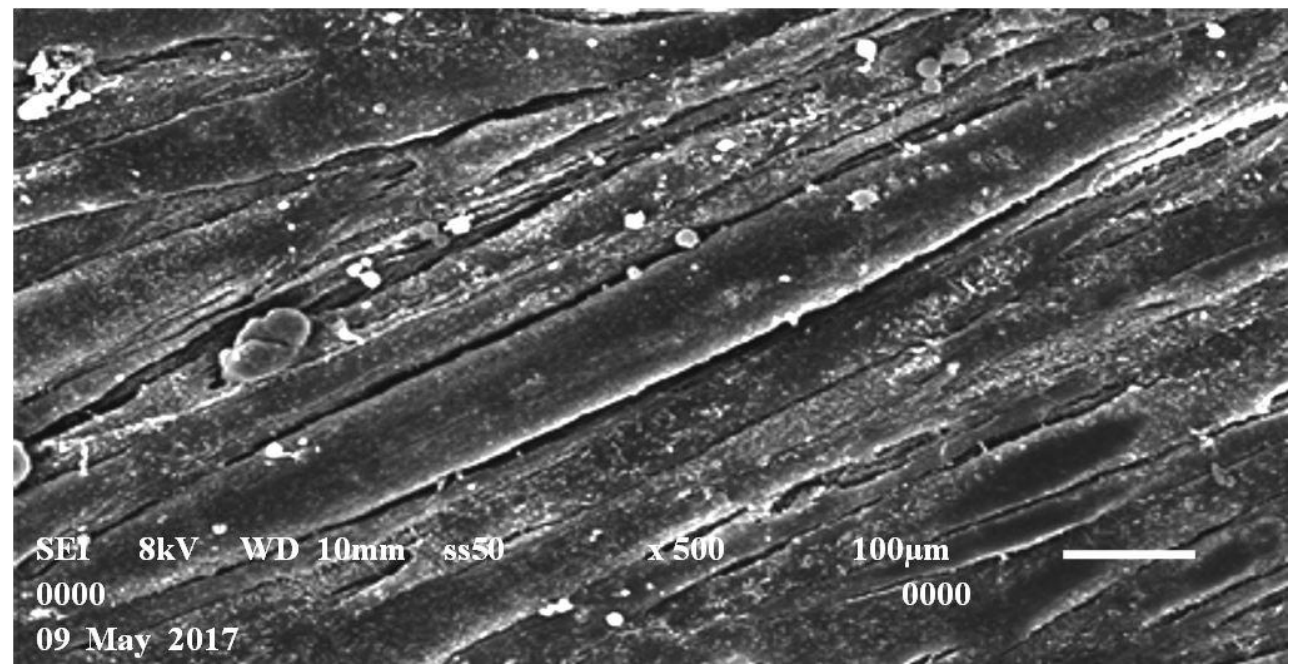

Fig.4 The Scanning electron microscopy of the trans-differentiated skeletal myocyte grown on gelatin coated coverslips reveals the presence of striations and adherence to the gelatin scaffold

The electron microscopy for the scanning of the cells was performed after 24 days of the trans-differentiation procedure to observe and validate that the cells trans-differentiated to skeletal myocytes. The scanning electron microscopy after 24 days of incubation of mesenchymal stem cells in the skeletal myogenic differentiation media revealed the presence of trans-differentiated skeletal myocytes. The cells when cultured in the skeletal myogenic media on the gelatin coated coverslips revealed the morphology of cells as flattened and with more than 2 nucleii in one cell. The cells aligned in longitudinal manner with each other in the tissue culture flasks and proliferated well. The cells were seen as longitudinal bands with striations (Figure 4). The majority of the skeletal myocytes formed 
were in clusters as they aligned in a longitudinal manner with each other. The cells were seen as longitudinal bands with striations and they were aligned to each other.

With this research study it might be concluded that the mesenchymal stem cells aspirated from bone marrow of the animal can be trans-differentiated to skeletal myocytes in vitro. These skeletal myocytes can be utilised to treat the inherited diseases of muscles and traumatic conditions which cause muscular loss in animals.

\section{Acknowledgement}

Authors express my thankfulness to Dr. Narendra Singh Jadon, my guide, Chairman of advisory committee. My heart is full of gratitude for my parents who have lead the way to my beautiful future. My self and my soul would be falsified if I fail to express my gratitude and affection for my wife Shakshi Bisht for being by my side in the times good and bad. The feelings of my heart lay bare before my respected seniors Dr.S. Arun Kumar Saini, Nitin Kandpal \& Rashmi Saini for their incessant support.

\section{References}

Du, M., Huang, Y., Lu, N., Shu, G., Zhu X., Wang L., Gao, P., Xi, Q., Zhang, Y., Wang S., Jiang, Q. 2014. Characterization and Differentiation into Adipocytes and Myocytes of Porcine Bone Marrow Mesenchymal Stem Cells. J. of Integr. Agri. 13(4): 837-848.

Gang, E. J., Jeong, J. A., Hong, S. H., Hwang, S. H., Kim, S. W., Yang, I. H., Ahn, C., Han, H. and Kim, H. 2004. Skeletal Myogenic Differentiation of Mesenchymal Stem Cells Isolated from Human Umbilical Cord Blood. Stem Cells 22:617-624.
Ghiban,N., Bortun,M., Bordeasu, I., Ghiban, B., Faur,N. and Cernescu, A. 2010. Evaluation of mechanical properties by stereo-and scanning electron microscopy of some heat curing dental resins, Mat. Plast. 47(2) :240.

Griffin, M.D., Elliman, S.J., Cahill, E., English, K., Ceredig, R. and Ritter T. 2013. Concise review: adult mesenchymal stromal cell therapy for inflammatory diseases: how well are we joining the dots? Stem Cells 31:2033-2041, http://dx.doi.org/10.1002/stem.1452.

Huang, S., Wang, K., Xu, L., Li, G., Sun, Y. and $\mathrm{Wu}$, Tianyi. 2015. An improved protocol for isolation and culture of mesenchymal stem cells from mouse bone marrow. J. of Orth. Trans.3: 2633.

Jadon, N.S., Kumar, A., Sarma, B. and Singh, S.P. 1998. Detomidine as a preanesthetic in thiopentone anesthesia in dogs. Indian J Anim Sci, 68: 48 .

Klepsch, S., Jamnig,A., Trimmel, D., Schimke, M., Kapferer, W., Brunauer, R., Singh, S., Reitinger, S. and Lepperdinger, G. 2013. Isolation of Mesenchymal Stem Cells from Human Bone and Long-Term Cultivation Under Physiologic Oxygen Conditions. Meth. In Mol. Biol. 976: 99-109.

Merrison, A.F.A., Gordon, D. and Scolding, N.J. 2012. Human Adult Bone Marrow-Derived Mesenchymal Stem Cells: Factors Influencing Skeletal Muscle Differentiation. J. Cell Sci. Ther. (4):001. doi:10.4172/21577013.S4-001.

Mizuno, H. 2010. The potential for treatment of skeletal muscle disorders with adipose derived stem cells, Curr. Stem Cell Res. Ther. 5 133-136, http://dx.doi.org/10.2174/1574888107 
91268573.

Mizuno, H., Zuk, P.A., Zhu, M. 2002. Myogenic differentiation by human processed lipoaspirate cells. Plast. Reconstr. Surg.;109:199-209.

Monica, G., Sara, C., Deborah, R., Katia, M., Fiorella, S., Michela, M., Elena, S., Laura, C., Ivana, F. and Franca, F. 2012. Validation of analytical methods in GMP: the disposable Fast Read $102^{\circledR}$ device, an alternative practical approach for cell counting. J. Transl. Med., 10: 112.

Pérez-Silos, V., Camacho-Morales, A., and Fuentes-Mera, L. 2016. "Mesenchymal Stem Cells Subpopulations: Application for Orthopedic Regenerative Medicine,"
Stem Cells Int.,Article ID 3187491, 9 pages, 2016. doi:10.1155/2016/3187491.

Snedecor, G. W. and Cochran, W. G. 1994. Statistical methods, 7th Ed. Oxford and I. B. M. Publication, Bombay.

Strober, W. 2001 Trypan blue exclusion test of cell viability. Curr. Protoc. Immunol., 21: 3B:A.3B.1.

Ueda, T., Araki, N., Mano, M. 2002. Frequent expression of smooth muscle markers in malignant fibrous histiocytoma of bone. J. Clin. Pathol.;55:853-858.

Zuk, P.A., Zhu, M. and Ashjian, P. 2002. Human adipose tissue is a source of multipotent stem cells. Mol Biol Cell. 13:4279-4295.

\section{How to cite this article:}

Sandhu. R. S., N. S. Jadon, P. Pandey, D. Bodh, P. Joshi, M. Kandpal, R. Saini and Kumar. A. 2020. Assessment of Invitro Differentiation Potential of Canine Bone Marrow Derived Mesenchymal Stem Cells to Skeletal Myocytes. Int.J.Curr.Microbiol.App.Sci. 9(06): 13801387. doi: https://doi.org/10.20546/ijcmas.2020.906.170 